\title{
O papel da biblioteca universitária na inclusão de alunos com deficiência no ensino superior
}

The role of the academic library in the inclusion of students with

disabilities in higher education

\author{
Eliane Maria Stroparo* \\ Universidade Federal do Paraná \\ Laura Ceretta Moreira** \\ Universidade Federal do Paraná
}

Resumo Apresenta reflexões sobre a educação como um direito de todos e a relevância das bibliotecas universitárias na inclusão dos alunos com deficiência no ensino superior. Visa analisar a educação inclusiva no ensino superior e compreender os processos pelos quais se articula com as bibliotecas universitárias. A pesquisa baseou-se em referencial teórico com enfoque crítico-descritivo. A coleta de dados foi efetuada por meio de observações em 10 bibliotecas, e entrevistas semiestruturadas com os bibliotecários do Sistema de Bibliotecas da Universidade Federal do Paraná (SiBi/UFPR) e 17 alunos com deficiência matriculados na UFPR. A análise dos dados fundamentou-se na análise de conteúdos. Evidencia-se a necessidade da implantação de política institucional inclusiva para erradicação de barreiras e favorecimento no acesso e permanência com sucesso de alunos com deficiência no ensino superior.

PALAVRAS-CHAVE: Educação especial; Políticas inclusivas; Acessibilidade; Biblioteca universitária.

Abstract This study presents considerations about education as everyone's right and the academic libraries relevance in the inclusion of students with disabilities. It aims to analyzethe inclusive education in higher education and to understand the processes by which it interacts with academic libraries. The research was developed using theoretical references with a critical and descriptive approach. The data collection was made through observations in 10 (ten) libraries, and semi-structured interviews with librarians from the Federal University of Paraná (UFPR) Library System $(\mathrm{SiBi})$ and 17 (seventeen) students with disabilities at UFPR. The data analysis was made based on content analysis ground. It demonstrates the need to implement institutional policy of inclusion in order to eradicate obstacles and to improve a successful access and retention of students with disabilities in Higher Education.

KEYWORDS: Special education; Inclusive policies; Accessibility, Academic library. 


\section{Introdução}

Com a política de inclusão educacional no Brasil, desencadeada na década de 1990, evidencia-se um aumento no número de matrículas dos alunos com deficiência no ensino superior, levando-se em conta a exclusão desse segmento da população ocorrida durante as décadas anteriores.

A Constituição Federal (CF) de 1988 é o ponto de partida de destaque aos direitos às pessoas com deficiência, e ao compromisso da universidade com o direito à educação, à acessibilidade e à inclusão. Não se pode perder de vista que a universidade deve desempenhar um papel democratizador junto à sociedade e colocar-se contra a exclusão social e a privatização dos conhecimentos, como bem lembra Chauí (2003). Nesse sentido, as bibliotecas universitárias, foco central deste estudo, precisam estar alinhadas a esse cenário.

Compete às bibliotecas universitárias prover à comunidade acadêmica, incluindo os que apresentam limitação visual, física e surdez, recursos de informação, oferecendo serviços e produtos diferenciados às suas limitações e potencialidades. (PUPO, MELO, FERRES, 2008).

Diante disso, precisam ser garantidas possibilidades de acesso iguais e justas a todos, criando-se ambientes que ofereçam recursos tanto em termos de espaço físico, como acervo e capacitação pessoal. As bibliotecas universitárias apresentam-se com o mérito de buscar, por meio de tecnologia de informação, formas alternativas para compartilhar e contribuir no processo de aprendizagem, possibilitando o acesso ao conhecimento e favorecendo a garantia do direito à educação.

Dessa forma, este artigo, para fins didáticos, apresenta-se subdividido em seções que tratam respectivamente da educação como um direito de todos; a produção do conhecimento sobre inclusão e acessibilidade no ensino superior e bibliotecas universitárias; o alunado que apresenta deficiência na UFPR; a biblioteca universitária e a inclusão de alunos com deficiência; assim como, aborda a acessibilidade no SiBi/ UFPR; por fim, apresenta a conclusão e a listagem das referências utilizadas.

\section{Educação: um direito de todos}

Cury (2002) pondera que o acesso à educação é um direito garantido por lei em praticamente todos os países, e que a legislação age como instrumento de luta para a criação de condições de democratização da educação e também para a socialização de gerações mais iguais e menos injustas.

Particularmente no Brasil, a partir da CF (1988) foram garantidos os direitos à educação a todos. No art. 208 , inciso $2^{\circ}$. está previsto o atendimento educacional especializado, preferencialmente na rede regular de ensino, às pessoas com deficiência. $\mathrm{O}$ art. $3^{\circ}$ estabelece como papel do Estado promover o bem de todos sem preconceito de origem, raça, sexo, cor, idade e quaisquer outras formas de discriminação. E já o art. $5^{\circ}$ reafirma a igualdade de todos perante a lei, sem distinção de qualquer natureza (BRASIL,1988). 
Assim, a educação brasileira, em todos os níveis e modalidades, começa a viver um processo de mudanças motivado pelo movimento da inclusão social e educacional. Para tanto, se faz necessária, sobretudo, uma formação de professores que primem tanto pela inclusão, compreendendo prédios e acervos acessíveis, centros ou núcleos de apoios pedagógicos e tecnologia assistiva, bem como por práticas pedagógicas abertas às diversidades do processo de ensino-aprendizagem.

Nessa perspectiva, as políticas de ações afirmativas são apresentadas como uma possibilidade para a promoção da justiça social no ensino superior, visando garantir - com base em leis e decretos, nos ambientes federais, estaduais e municipais - a igualdade de direito à educação para todos.

A preocupação com os direitos da pessoa com deficiência existe na legislação nacional e internacional. Contudo, o que se questiona é a sua aplicação: em que medida essas leis são suficientes para determinar os direitos e, ainda, quais são seus avanços e entraves.

O acesso dos alunos com deficiência ao ensino superior levanta um questionamento a respeito das condições desse segmento de ensino, não apenas no que se refere ao ingresso, mas à permanência e ao sucesso desses alunos. Embora as ações de apoio na universidade estejam presentes, as mudanças necessárias para responder às demandas ainda representam inúmeros desafios.

Os dados obtidos do Instituto Nacional de Estudos e Pesquisas Anísio Teixeira (INEP) (2013) mostram que o número de matrículas de alunos com deficiência em instituições de ensino superior, públicas e particulares, passou de 5.078 para 29.034 de 2003 a 2013. Embora ainda irrisórios esses números já representam uma mudança no quadro do ensino superior. O crescimento evidencia a implantação e efetivação de políticas públicas de inclusão e programas de ações afirmativas que visam o respeito à diversidade e à igualdade social.

A análise dos indicadores demonstra um salto no número de matrículas de alunos com deficiência. Entretanto, o desafio é o alcance de dados qualitativos, ou seja, políticas de ações que demarquem uma permanência de qualidade e a perspectiva de que esses futuros profissionais serão incorporados ao mercado de trabalho.

\section{Produção do conhecimento sobre inclusão e acessibilidade no ensino superior e bibliotecas universitárias}

Traçar um panorama do referencial teórico é importante para identificar, conhecer e analisar a produção científica sobre inclusão, acessibilidade e bibliotecas universitárias.

Como fonte de pesquisa, foi utilizado o Portal da Capes, procedendo-se a pesquisa pelo Banco de Teses e Dissertações da Coordenação de Aperfeiçoamento de Pessoal de Nível Superior (CAPES), na base Biblioteca Digital Brasileira de Teses e Dissertações (IBICT) e no portal Scielo. O levantamento foi expandido para portais de bibliotecas nacionais, ao Banco Bibliodata, Revista de Educação Especial de Santa 
Maria, Revista Brasileira de Educação Especial da Associação Brasileira de Pesquisadores em Educação Especial, e também aos seguintes eventos: Associação Nacional de Pós-Graduação e Pesquisa em Educação (ANPED), Seminário Nacional de Bibliotecas Universitárias (SNBU) e Congresso Multidisciplinar de Educação Especial, procedendo a busca sob o período de 2000 a 2014.

Inicia-se apontando a pesquisa de Cunha (2000), que analisa as mudanças enfrentadas pelas bibliotecas universitárias, sobretudo as afetadas pelas tecnologias da informação. $\mathrm{O}$ autor prenuncia mudanças estruturais (ênfase no atendimento e na terceirização de serviços), no financiamento (consórcios visando à redução de custos), nos serviços (balcão de referência eletrônico, suporte a programas de ensino a distância) e quanto ao público (diversidade de clientela). $\mathrm{O}$ pesquisador destaca que a biblioteca universitária deve examinar as possibilidades do futuro e entender que o maior desafio será atender às necessidades da clientela em mudança, compreendendo-o como uma oportunidade de renovação.

Mazzoni et al. (2001) discutem o conceito de acessibilidade do projeto Livre de Barreiras - atualmente conhecido como Desenho para Todos - englobando tanto aspectos do mundo físico como do digital. Os autores advertem que as bibliotecas universitárias, no quesito acessibilidade, passaram a chamar a atenção do Ministério da Educação e Cultura (MEC), a partir de 1999, com a publicação da Portaria n. 1.679, que dispõe sobre a exigência de acessibilidade para pessoas portadoras de deficiência ${ }^{2}$, para instruir os processos de autorização e de reconhecimento de cursos, bem como o credenciamento de instituições.

Silveira (2001) analisa o papel das bibliotecas universitárias - o de prover recursos informacionais à comunicação acadêmica - a fim de subsidiá-las nas suas atividades de ensino, pesquisa e extensão. Destaca o descaso para com os deficientes, prevalecendo barreiras arquitetônicas, inacessibilidade à informação disponibilizada, inexistência de tecnologias alternativas, alegando-se o pequeno número de pessoas portadoras de deficiência nas instituições de ensino superior. Essa justificativa, por sua vez, confronta-se com as estatísticas, que mostram índice elevado de deficientes nessa faixa etária/segmento.

O trabalho de Oliveira (2003) identifica, descreve e analisa sob o ponto de vista do estudante com deficiência em relação às condições de acessibilidade na Universidade Estadual de Londrina. Relata a autora a respeito da biblioteca:

Os participantes revelaram a existência das barreiras arquitetônicas que impediam o acesso a todos os serviços da biblioteca, a dificuldade para retirar os livros da estante, o ir e vir à biblioteca. Evidencia-se a falta de comunicação entre o participante e a biblioteca, o que impossibilita o acesso e a interação entre ambos. Consequentemente, há uma limitação do convívio do participante no espaço acadêmico. (OLIVEIRA, 2003, p. 135).

A pesquisa de Moreira (2004) versa sobre o processo de inclusão de alunos com necessidades educacionais especiais de três cursos de licenciatura da UFPR. Pela abordagem qualitativa, a autora buscou conhecer as iniciativas e ações na universidade 
- observando em que medida essas contribuíram para o ingresso e permanência desses alunos - assim como as práticas pedagógicas adotadas pelos professores, a formação acadêmica e a importância da biblioteca nesse processo.

A dissertação de Souza (2004) visa propor uma metodologia para estruturar serviços informacionais aos usuários com deficiência visual em bibliotecas universitárias de Instituições de Ensino Superior (IES). A autora lembra que a criação e a disseminação do conhecimento são o maior foco das universidades. Nesse sentido, devem ser garantidas às pessoas com deficiência a inclusão por meio da educação e informação, e a promoção das relações de aprendizagem a partir do espaço da biblioteca universitária.

Pela (2006), em sua pesquisa, analisa os anseios dos estudantes deficientes visuais em relação à biblioteca, identificando dificuldades e possibilidades na utilização da biblioteca como um espaço formativo. A autora, preocupada com a inclusão dos deficientes visuais, observa que a primeira modificação que o deficiente visual necessita é a adaptação do material informacional, passando o impresso à tinta para o formato digital - produto inexistente no mercado editorial. A biblioteca, para atendê -los, necessita adaptar a informação em meio digital, braile ou MP3.

O estudo de Melo e Medeiros (2007) situa as ações desenvolvidas e em andamento na Universidade Federal do Rio Grande do Norte (UFRN) que visam garantir o acesso e a qualidade do ensino aos alunos com deficiência. Os documentos analisados foram baseados em relatórios provenientes da Pró-Reitoria de Graduação (PROGRAD) e projetos institucionais. Relatam os autores

\begin{abstract}
A Biblioteca Central Zilda Mamede criou uma área física denominada espaço inclusivo [...] adotou uma política de desenvolvimento da sua coleção que privilegiasse o acesso a pessoa com deficiência visual, por meio de obras em Braille, a exploração das fontes eletrônicas por meio de textos sonoros e também a ampliação do acervo geral que atenda a demanda de informação/conhecimento voltada para a área da deficiência. (MELO; MEDEIROS, 2007, não paginado).
\end{abstract}

Paula (2009), em seu estudo, propõe uma disciplina que contribua com a formação do bibliotecário para o atendimento da pessoa com deficiência nas bibliotecas universitárias. O estudo demonstra que em dois cursos de graduação em Biblioteconomia há disciplinas relacionas com a inclusão.

Menegatti (2012) descreve a temática da acessibilidade voltada aos serviços de informação aos deficientes visuais das bibliotecas universitárias das IES de Florianópolis. A reflexão da autora objetiva auxiliar a tornar os serviços de informação mais eficazes para as pessoas com deficiência visual, visando sua permanência no ensino superior.

Silva (2012) discorre sobre as ações informacionais utilizadas para o atendimento das necessidades socioinformacionais dos alunos cegos do Campus I da Universidade Federal da Paraíba (UFPB), identificando suas necessidades informacionais e barreiras na busca e uso da informação. A autora aponta que 
[...] ao buscar a informação, o indivíduo percorre caminhos para alcançar seus objetivos informacionais, porém as limitações estão sempre presentes e condicionam essa busca a uma parcialidade de conhecimento que, agregado a valores próprios individuais, tem uma validade efetiva do usufruto dessa informação. (SILVA, 2012, p. 105).

A pesquisa de Malheiros (2013) apresenta um estudo que se propõe a identificar as necessidades de informação de usuários com deficiência visual da Biblioteca Digital e Sonora da Universidade de Brasília, e colher subsídios para a definição de uma política de desenvolvimento de coleções. A pesquisadora relata que

[...] a informação em meio digital é fundamental para os usuários, sendo a mais utilizada, seguida da informação em áudio e braile; os usuários acessam todo tipo de informação no computador, mas buscam principalmente didáticas e profissionais, tendo suas necessidade de informação a maior parte satisfeitas. (MALHEIROS, 2013, p. 6).

Já o estudo de Sousa et al (2014) explora o tema da inclusão educativa da pessoa com deficiência na educação superior, e trata das ações desenvolvidas pelo Sistema de Bibliotecas da Universidade Federal do Ceará na tentativa de garantir a permanência com qualidade desses alunos.

O presente levantamento de estudos possibilita uma visão do estado do conhecimento da comunidade acadêmica acerca de políticas inclusivas, acessibilidade no ensino superior e em bibliotecas universitárias, assim como evidencia o quanto a qualidade da formação acadêmica do alunado que apresenta deficiências passa por algumas dificuldades, seja de ordem física, atitudinal, informacional, tecnológica ou pedagógica.

\section{Alunos com deficiência na Universidade Federal do Paraná}

A partir de 1997, surge na UFPR o Grupo de Trabalho sobre a Pessoa com Necessidades Especiais (GPTNE), responsável pelas primeiras ações na universidade em prol da inclusão - organizando palestras, orientando professores e produzindo materiais sobre a temática (MOREIRA, 2012).

A UFPR organiza a infraestrutura física e pessoal e inaugura o Núcleo de Apoio às Pessoas com Necessidades Especiais (NAPNE) em 2006, vinculado à Pró-Reitoria de Graduação (PROGRAD), inserido em 2008 na Coordenação de Estudos e Pesquisas Inovadoras na Graduação (CEPIGRAD), com o objetivo principal de oferecer alternativas à inclusão e à permanência de pessoas com necessidades especiais (alunos, professores e servidores) na UFPR (UNIVERSIDADE FEDERAL DO PARANÁ, 2013).

Ressalta-se como ação da UFPR em busca da inclusão a aprovação da Resolução interna n.70/08, a qual amplia a política de ingresso e de permanência de alunos com deficiência na UFPR por meio da liberação de investimentos na infraestrutura física e de pessoal, e da aprovação de destinação de uma vaga preferencial em cada curso de graduação, seja presencial ou a distancia, e de ensino profissionalizante e 
ensino médio (UNIVERSIDADE FEDERAL DO PARANÁ, 2008).

Em 2013, a UFPR contava com 79 alunos com necessidades educacionais especiais ${ }^{3}$. Dentre esses, 51 com deficiências - cujo ingresso ocorreu pelos processos seletivos do vestibular, provar $^{4}$ e seleção em programas de pós-graduação (MOREIRA, 2013). Destaca-se que o alunado com deficiência aqui evidenciado é composto por aqueles que apresentam deficiência física, visual, surdez e múltipla.

Frente às políticas públicas e à efetividade dos aparatos legais direcionadas ao ingresso, à permanência e à conclusão do ensino superior pelos alunos com deficiência, destaca-se o papel da biblioteca universitária como sendo decisivo no processo educacional por meio da disponibilização e acesso à informação necessária ao desenvolvimento intelectual e acadêmico de todos os alunos - não perdendo de vista que o direito à educação é para todos os cidadãos, o que implica no reconhecimento de que as diferenças exigem atendimentos específicos para que se assegure tal princípio.

\section{Biblioteca universitária e a inclusão de alunos com deficiência}

As transformações que a sociedade contemporânea enfrenta são estendidas à universidade - o que não poderia ser diferente, já que a universidade é constituída do social e, consequentemente, o social é constituído da universidade (CHAUÍ, 2001). A universidade é entendida como uma instituição social para atender às necessidades da sociedade em geral, considerando as diferentes necessidades, em prol do desenvolvimento da educação, da ciência e da cultura. A partir dessa perspectiva as bibliotecas universitárias entram em uma fase de transformação, buscando adaptar-se às mudanças econômicas e tecnológicas que influenciam a socialização do conhecimento.

Levando-se em conta que as universidades e as bibliotecas são instituições sociais que desempenham o papel de ora criar o conhecimento, e ora facilitar o acesso a esse conhecimento, essas também são atingidas pelas mudanças e, então, chamadas a refletir sobre seu papel nesse contexto (CARVALHO, 2004).

Coloca-se às bibliotecas universitárias o desafio de assumir novos serviços para atender às exigências da universidade, em que se destaca o atendimento aos alunos com deficiência - garantindo, assim, acessibilidade a todos os alunos, oferecendo serviços e informação em formatos diferenciados.

Dessa forma, cabe à biblioteca universitária prover, além da acessibilidade e adaptação do espaço físico, a promoção da informação aos indivíduos da comunidade universitária, inclusive aqueles com qualquer tipo de deficiência, sem discriminação. Assim, é importante atender às necessidades específicas oferecendo acesso à informação em diferentes formatos, contribuindo para a formação intelectual e da cidadania.

Nesse contexto, a definição de acessibilidade está contida no Decreto $n^{\circ}$. 5.296, de 22 de dezembro de 2004 ,

[...] como sendo a condição para utilização, com segurança, autonomia, total ou assistida, aos espaços, mobiliários e equipamentos urbanos, às edificações, aos serviços de transporte, aos sistemas e 
meios de comunicação e informação, por pessoas com deficiência ou com mobilidade reduzida. (BRASIL, 2004).

Manzini (2003, p. xxiii) alerta que

Apesar de a associação do termo acessibilidade ao termo inclusão ser coerente e lógica, é hipoteticamente possível que um ambiente arquitetônico esteja totalmente adaptado, mas a inclusão social não ocorra, ou seja, podemos dizer que a acessibilidade pode auxiliar na inclusão, mas a inclusão não ocorre somente por meio da acessibilidade.

A aplicabilidade da inclusão e acessibilidade nas bibliotecas universitárias ocorrem a partir do respeito às diferenças, mudanças de atitudes, e efetivação de políticas públicas institucionais. Destaca Pela (2006, p.59) que a inclusão em uma biblioteca se dá quando sua porta se abre para receber todo o público sem qualquer distinção, mesmo que seja com necessidades diferentes dos demais, e consiga, interagindo, compreender suas necessidades e proporcionar um serviço diferente. (PELA, 2006, p. 59).

\section{Acessibilidade no sistema de bibliotecas da Universidade Federal do Paraná}

No processo educacional inclusivo, entre as ações desenvolvidas pelas universidades, as bibliotecas universitárias recebem atenção especial - cabendo a elas fornecer a informação necessária para o desenvolvimento dos alunos com deficiência, facilitando a sua permanência, melhorando a qualidade de sua formação e, assim, contribuindo para diminuir o índice de evasão.

Para responder ao desafio de ampliar o debate sobre políticas públicas de atendimento aos alunos com deficiência e posicionar as bibliotecas universitárias no plano de implantação de políticas de educação inclusiva na universidade, esta pesquisa de natureza mista, qualitativa/quantitativa e exploratória com enfoque crítico-descritivo e documental, analisa e discute as políticas de inclusão e acessibilidade no ensino superior, tendo como recorte específico o Sistema de Bibliotecas da UFPR.

Fazem parte da presente pesquisa ${ }^{5}$ os estudantes com deficiência da UFPR, as bibliotecas do $\mathrm{SiBi} / \mathrm{UFPR}$ e os chefes das respectivas bibliotecas, aqui denominados gestores.

Para efeito de cálculo na escolha dos participantes foi utilizada a técnica de amostragem: dos 79 alunos com necessidades educacionais especiais da UFPR foram selecionados 51 (com deficiência física, visual, surdez e múltipla), calculando-se o tamanho da amostra em 17 estudantes de graduação com deficiência - que representam $33 \%$ da população. Quanto às bibliotecas observadas in loco e seus respectivos gestores entrevistados, o número de amostra foi fixado em 10.

No desenvolvimento da pesquisa foi elaborado um roteiro para observação 
in loco nas bibliotecas objetivando analisar suas condições gerais de acessibilidade e inclusão; já as entrevistas semiestruturadas com gestores visaram identificar as ações implementadas e as barreiras existentes para atender os alunos com deficiência.

A organização e análise de conteúdo das falas dos sujeitos da pesquisa ocorreram de acordo com as categorias tomadas na elaboração do roteiro para observação, visto que não foram evidenciadas (por meio dos depoimentos dos entrevistados) novas categorias de análise - ou seja: acessibilidade física, acessibilidade informacional, acessibilidade atitudinal, acessibilidade nos serviços oferecidos, e política institucional inclusiva. $\mathrm{Na}$ sequência, apresentam-se os principais dados mapeados a partir da analise das categorias.

A respeito desta pesquisa, é importante destacar que a identificação dos participantes preservou seu anonimato, referenciando-os na pesquisa por letras - sendo utilizadas da seguinte maneira: para os alunos a letra $A$, para as bibliotecas a letra $B$ e para os bibliotecários as letras Bib seguidas de números sequenciais aleatórios.

No que se refere à acessibilidade física, o estudo baseou-se em parâmetros estabelecidos pela NBR 9050 (ABNT, 2004) com análise dos elementos: acesso as dependências, mobiliário, mobilidade e sinalização - os quais receberam valores de zero a quatro, sendo que zero não se aplica, um não existe, dois não atende, três atende parcialmente e quatro atende totalmente. Nesse caso, foram analisadas as 10 bibliotecas, tendo seus valores explorados da seguinte forma: acima de $90 \%$ foram consideradas adequadas, de 89 a $60 \%$ parcialmente adequadas e abaixo de $60 \%$ inadequadas.

No que diz respeito à acessibilidade informacional, foram analisados os acervos em diferentes formatos: braile, áudio e outros, presentes e/ou ausentes no $\mathrm{SiBi} /$ UFPR, assim como as tecnologias de informação e comunicação (TIC).

Com relação à acessibilidade atitudinal, evidencia-se o elemento invisibilidade do aluno com deficiência, o qual não foi contemplado no roteiro de entrevistas, porém, destaca-se nos depoimentos dos gestores com a postura de reconhecimento ou não. Nessa categoria também foram analisados os atendimentos prestados pelos servidores, a capacitação profissional e as mudanças de atitudes. Já ao que tange à acessibilidade de serviços foram estudados os serviços tradicionalmente oferecidos, como: empréstimo, renovação, reserva on-line, utilização de livros digitais, solicitação de cópia de artigos e partes de livros, entre outros, e também serviços exclusivos ofertados para atender às diferentes necessidades, presentes e/ou ausentes no $\mathrm{SiBi} / \mathrm{UFPR}$.

Com relação à política institucional, destaca-se que o $\mathrm{SiBi} / \mathrm{UFPR}$ oferta serviços exclusivos para atender às diferentes necessidades dos alunos e, além disso, busca a obtenção de recursos financeiros específicos para adequação das bibliotecas às normas de acessibilidade e a capacitação profissional. Contudo, evidenciam-se ainda dificuldades na concretização em todos os campi com relação à acessibilidade física: apenas uma das bibliotecas pesquisadas mostra-se adequada, cuja preocupação vem ocorrendo desde 2007; quatro bibliotecas necessitam principalmente de redimensionamento de layout, de adaptações nos mobiliários, que são incompatíveis com as medidas estabelecidas pelas normativas, adaptações nos banheiros e também nos be- 
bedouros; e em cinco bibliotecas a atenção deve ser focada na remoção de catracas, escadas e instalação de elevador ou rampa de acesso para as bibliotecas com mais de um pavimento.

Os depoimentos dos estudantes ilustram o problema de acessibilidade nos balcões de atendimento nas diferentes bibliotecas. Referindo-se à B4, o A4 relata que: "para mim o balcão é muito alto, não consigo alcançar o teclado para digitar a senha no momento do empréstimo, sugiro que se providencie uma parte mais baixa e com recuo" (A4, entrevistado pela pesquisadora em 24/10/2013). O relato do Bib 5 demonstra a atenção com a acessibilidade no planejamento do balcão de atendimento: "A gente trocou o balcão, priorizamos um nem alto nem baixo, tentamos deixar compatível com a norma, enfim, tentamos deixar da forma mais prática possível" (Bib5, entrevistado pela pesquisadora em 17/9/2013).

Com relação à acessibilidade informacional, os serviços oferecidos destacam o acesso às informações impressas, disponíveis fisicamente nas bibliotecas, e também no Portal da Informação (www.portal.ufpr.br). Não há duplicação de acervo em formatos diferentes, cuja carência é suprida pela disponibilização de equipamentos e recursos tecnológicos presentes em uma biblioteca que atua como unidade piloto para todo $\mathrm{SiBi}$. Esses recursos permitem transformar o conteúdo impresso em sonoro, tornando acessível a informação contida em livros, revistas impressas, e em páginas da Internet. O A1 relata que, além da Internet, não tem conhecimento de recursos e equipamentos com tecnologias assistivas e, então, buscava os recursos bibliográficos por meio de outras fontes. "O que fazia na B4 era emprestar o livro a tinta, os meus colegas, monitores de turma e amigos davam um jeito, contei muito com a ajuda deles" (A1, entrevistado pela pesquisadora em 21/10/2013).

$\mathrm{Na}$ acessibilidade atitudinal, os depoimentos marcam os atendimentos dos servidores como sendo de atenção, prontidão e boa vontade. Os gestores das bibliotecas destacam dificuldades em lidar com as diferenças, evidenciando a importância de mais capitação para atender às diferentes necessidades educacionais.

No relato do A10, observa-se que os servidores são atenciosos, solícitos e demonstram boa vontade:

A nota que dou no atendimento da B1 de 1 a 10 é 11. As pessoas que atendem são excepcionais. No primeiro dia que adentrei nesse espaço já veio um servidor preocupado com o atendimento. (A10, entrevistado pela pesquisadora em 29/10/2013).

Quanto à categoria acessibilidade de serviços, destacam-se como satisfatórios os serviços tradicionais; a inexistência de recursos informacionais específicos evidencia-se em nove bibliotecas, sendo que apenas uma biblioteca oferece esses recursos. O A7 relata que "o uso do portal da biblioteca para localizar os livros e o serviço de empréstimo por meio do envio de avisos de devolução e atraso de materiais são facilitadores para meus estudos" (A7, entrevistado pela pesquisadora em 25/10/2013).

$\mathrm{Na}$ análise da política institucional da instituição, destacam-se a demanda 
pela alteração no regulamento de empréstimo, ampliando o prazo de devolução de livros para alunos com deficiência; a presença da Comissão de Acessibilidade que visa discutir ações sobre a temática em todo $\mathrm{SiBi}$; a importância e urgência do estabelecimento de política institucional inclusiva, para a eliminação de barreiras; e o desenvolvimento de ações para favorecer a permanência e sucesso dos alunos com deficiência no ensino superior.

O Bib1, em seu relato, aponta aspectos para a política inclusiva, considerando importante

Notificação e encaminhamento dos alunos com deficiência pelo Núcleo de Concursos às coordenadorias e estas para as bibliotecas, para conbecimento de quantos e quem são os alunos. Formaçã̃o mais avançada dos profissionais pois existe apenas uma noção básica. Divulgação do que a biblioteca oferece, os alunos com deficiência não sabem a quem recorrer, quando ele descobre está se formando ou evadiu. (Bib1, entrevistado pela pesquisadora em 10/9/2013).

O A1 apresenta sugestões para a política inclusiva do $\mathrm{SiBi} / \mathrm{UFPR}$, afirmando que

Interessante pensar no aluno com deficiência visual oferecendo uma semana de conscientização antes do inicio das aulas. Acho que a biblioteca é uma possivel parceira para ajudar nessa questão, mostrando o acervo, produtos e serviços oferecidos. Isso já é oferecido, porém o protocolo não foi adaptado para alunos com deficiência. (A1, entrevistado pela pesquisadora em 21/10/2013).

\section{Conclusão}

A concretização de políticas inclusivas ainda é um dos maiores desafios da educação superior, visto que o reconhecimento das necessidades educacionais e do direito dos estudantes com deficiência, seja pela via do ingresso quanto pela permanência com sucesso, são obstáculos ainda existentes.

Por outro lado, o aumento do número de alunos com deficiência no ensino superior já representa uma importante mudança no quadro das IES. Todavia, a garantia do direito desses estudantes depende de políticas de estado que primam pela inclusão de todos, somado aos esforços de cada IES em efetivar ações inclusivas. Nesse contexto, é fundamental que sejam desenvolvidas condições facilitadoras, dentre elas o provimento de adequações das bibliotecas, uma vez que essas desempenham papel fundamental no processo educacional e formativo dos estudantes com deficiência.

Para que as bibliotecas universitárias sejam acessíveis e inclusivas é preciso assegurar políticas de forma permanente, possibilitando que a acessibilidade em todas as suas dimensões se dê de maneira plena, e não fragmentada e pontualmente. As condições de acessibilidade existentes no $\mathrm{SiBi} / \mathrm{UFPR}$, as tecnologias adequadas, o acervo especial e as adaptações nas instalações precisam ser ampliados para todos os espaços da instituição. 
Conclui-se que dentre as mudanças necessárias, a remoção de obstáculos e de barreiras, e a observância das leis de acessibilidade - para receber com atenção e qualidade os alunos com deficiência, contribuindo assim com o processo inclusivo no ensino superior - são fundamentais. Destaca-se também a importância da capacitação dos profissionais para atender às diferentes necessidades educacionais da comunidade universitária e para o uso dos recursos tecnológicos específicos. Além disso, e, sobretudo, a mudança de atitude ainda permanece como quesito fundamental na luta contra a exclusão. Por fim, a implantação de políticas inclusivas para fazer cumprir o direito do estudante com deficiência, transformar as condições adversas enfrentadas pelos mesmos e favorecer sua permanência no ensino superior é condição fundamental para assegurar sua cidadania.

\section{Referências}

ASSOCIAÇÃO BRASILEIRA DE NORMAS TÉCNICAS. NBR 9050: acessibilidade e edificações, equipamento e mobiliário urbano à pessoa portadora de deficiência. Rio de Janeiro, 2004.

BRASIL. Constituição (1988). Constituição: República Federativa do Brasil. Brasília: Senado Federal, 1988.

. Decreto n. 3.956/01 (Convenção de Guatemala) - Promulga a Convenção de todas as formas de discriminação contra as pessoas portadoras de deficiência. Disponível em:< http:// www.planalto.gov.br/ccivil_03/decreto/2001/d3956.htm>. Acesso em: 10 jan. 2013.

. Decreto n. 5.296, de 22 de dezembro de 2004. Regulamenta as leis n.10.048, de 8 de novembro de 2000, que da prioridade de atendimento as pessoas que especifica, e 10.098 , de 19 de dezembro de 2000, que estabelece normas gerais e critérios básicos para a promoção da acessibilidade das pessoas portadoras de deficiência ou com mobilidade reduzida, e da outras providências. Diário Oficial [da] República Federativa do Brasil, Brasília, D.F., 3 dez. 2004. Disponivel em: <http://www.mj.gov.br/sedh/ct/CORDE/dpdh/sicorde/dec5296.asp>. Acesso em: 10 jan. 2013.

. Decreto n. 186/08 - aprova o texto da Convenção sobre os Direitos das Pessoas com Deficiência e de seu protocolo facultativo, assinado em Nova Iorque, em 30 de março de 2007. Disponível em: <http://portal.mec.gov.br/dmdocuments/decreto186.pdf>. Acesso em: 1 jan. 2013.

. Decreto n. 7.611 de 17 de novembro de 2011. Dispões sobre a educação especial. Diário Oficial [da] União. Brasília, DF, 18 nov. 2011. Seção 1, p. 12.

Decreto n. 7.612 de novembro de 2011. Institui o Plano Nacional dos Direitos da Pessoa com Deficiência - Plano Viver sem Limite. Diário Oficial [da] União. Brasília: 18 de nov. 2011. Seção 1, p. 12-13.

. Ministério da Educação SEESP. Política nacional de educação especial na perspectiva de educação inclusiva. Brasília, 2014. Disponível em: <http://wwwportal.mec.gov.br/index. php?option=com_c $>$. Acesso em: 15 jan. 2013.

. Ministério da Saúde.Conselho Nacional de Saúde. Resolução n. 466/2012. Diário Oficial [da] União, n.12, 13 jun. de 2013. p. 59. Seção1.

. Portaria n. 3.284/03. Dispõe sobre requisitos de acessibilidade de pessoas portadoras de deficiência, para instruir os processos de autorização e de reconhecimento de cursos e de credenciamento de instituições. Disponível em: <http://pt.slideshare.net/asustecnologia/porta- 
ria-3284-03>. Acesso em: 10 jan. 2003.

CARVALHO, J. C. L. A socialização do conhecimento no espaço das bibliotecas universitárias. Niterói: Intertexto, 2004.

CHAUÍ, M. Escritos sobre a universidade. São Paulo: Unesp, 2001.

CHAUÍ, M. A universidade pública sob nova perspectiva. In: Conferência de abertura da $\mathbf{2 6}^{\mathbf{a}}$ reunião anual da ANPED, Poços de Caldas, 5 de outubro de 2003.

CUNHA, M. B. Construindo o futuro: a biblioteca universitária brasileira em 2010. Ciência da Informação, Brasília, v. 29, n. 1, p. 71-89 jan./abr. 2000.

CURY, C. R. J. Direito à educação: direito à igualdade, direito a deficiência. Cadernos de Pesquisa, n. 116, p. 245-262, jul. 2002.

INSTITUTO NACIONAL DE ESTUDOS E PESQUISAS EDUCACIONAIS ANÍSIO TEIXEIRA - INEP. Censo da educação superior: 2011 - resumo técnico. Brasília, 2013.

MALHEIROS, T. M. de. C. Necessidade de informação do usuário com deficiência visual: um estudo de caso da Biblioteca Digital e sonora da Universidade de Brasília. 305 f. Dissertação (Mestrado em Ciências da Informação) - Universidade de Brasília, Brasília, 2013.

MANZINI, E. J. Introdução. In: MARQUEZINI, M. C. et al. Educação física, atividades motoras e lúdicas, e acessibilidade de pessoas com necessidades especiais. Londrina: Eduel, 2003. p. xxi-xxvi.

MAZZONI, A. A. et al. Aspectos que interferem na construção de acessibilidade em bibliotecas universitárias. Ciência da informação, Brasília, v. 30, n. 2, p. 29-34, maio/ago. 2001.

MELO, F. R. L. V.; MEDEIROS, R. Inclusão de alunos com deficiência no ensino superior: ações no contexto da Universidade Federal do Rio Grande do Norte. Trabalho apresentado no 4. Congresso Brasileiro Multidisciplinar de Educação Especial, Londrina, 2007.

MENEGATTI, Y. Serviço de informação acessíveis para deficientes visuais em bibliotecas de instituições de ensino superior no município de Florianópolis. $176 \mathrm{f}$. Dissertação (Mestrado em Ciência da Informação) - Universidade Federal de Santa Catarina, Florianópolis, 2012.

MOREIRA, L. C. Necessidades educacionais especiais e o processo de ensino e aprendizagem nos cursos de licenciatura da UFPR. Curitiba: UFPR, 2012. Relatório do Programa Licenciar.

Levantamento parcial de alunos com NEE com entrada pelos processos seletivos da UFPR a partir do ano de 2008. Curitiba: UFPR/NAPNE, 2013.

Universidade e alunos com necessidades educacionais especiais: das ações institucionais às práticas pedagógicas. Tese (Doutorado em Educação) - Faculdade de Educação, Universidade de São Paulo, São Paulo, 2004.

OLIVEIRA, E.T. G. Acessibilidade na Universidade Estadual de Londrina: o ponto de vista do estudante com deficiência. 168 f. Dissertação (Mestrado em Educação) - Faculdade de Filosofia e Ciências, Universidade Estadual Paulista, Marília, 2003.

PAULA, S. N. Acessibilidade à informação em bibliotecas universitárias e a formação do bibliotecário. 126 f. Dissertação (Mestrado em Ciências da Informação) - Pontifícia Universidade Católica de Campinas, Campinas, 2009.

PELA, M. A. P. A biblioteca universitária, espaços formativos e inclusão: a perspectiva de graduandos com deficiência visual. São Paulo, 2006. Dissertação (Mestrado). Universidade Cidade de São Paulo. 
PUPO, D. T.; MELO, A. M.; FERRES, S. P. Acessibilidade: discurso e prática no cotidiano das bibliotecas. Campinas: Unicanp, 2008.137p.

SILVA, A. M. Informação e inclusão acadêmica: um estudo sobre as necessidades sócio informacionais dos universitários cegos do Campus I da UFPB. 144 f. Dissertação (Mestrado em Ciência da Informação) - Universidade Federal da Paraíba, João Pessoa, 2012.

SILVEIRA, J. G. da. Biblioteca inclusiva? Repensando barreiras de acesso aos deficientes físicos e visuais dos sistema de bibliotecas da UFMG e revendo trajetória institucional na busca de soluções. In: SEMINÁRIO INTERNACIONAL SOCIEDADE INCLUSIVA, 1., 1999, Belo Horizonte. Anais... Belo Horizonte: Pontifícia Universidade Católica de Minas Gerais, 2001. p. 245-256.

SOUSA, C. et al. Acessibilidade a informação científica na educação superior: caminhos trilhados pelo Sistema de Bibliotecas da Universidade Federal do Ceará. Trabalho apresentando no $18^{\circ}$ Seminário Nacional de Bibliotecas Universitárias, Belo Horizonte, 2014.

SOUZA, S. C. Acessibilidade: uma proposta de metodologia de estruturação de serviços informacionais para usuários cegos e com visão subnormal em bibliotecas universitárias. $141 \mathrm{f}$. Dissertação (Mestrado em Engenharia de Produção) - Universidade Federal de Santa Catarina, Florianópolis, 2004.

UNIVERSIDADE FEDERAL DO PARANÁ. COUN. Resolução 70/08. Aprimora as políticas de ingresso e permanência de pessoas com deficiências na UFPR e aprova a destinação de uma vaga em cada curso de graduação, de ensino profissionalizante e de ensino médio para as pessoas deficientes a partir do processo seletivo 2008/2009 (vestibular). Curitiba, 2008.

Prograd-Cepigrad-Napne. Disponível em: <http:www.prograd.ufpr.br/cepigrad/napne.atml. Acesso em: 14 ago. 2013.

Prograd-Cepigrad-Napne. Candidatos aprovados portadores de necessidades especiais: 2014/2015. Curitiba, 2015.

Notas

${ }^{1}$ Dentre elas destacam-se: Decreto n. 3.956/01 (Convenção de Guatemala); Decreto n. 5.296/04; Decreto n. 186/08; Portaria n. 3.284/03; Decreto n. 7.611; e Decreto n. 7.612.

${ }^{2}$ Terminologia usada pela referida portaria.

${ }^{3}$ Alunos que apresentam deficiência, transtornos globais de desenvolvimento e altas habilidades/superdo-

* Bibliotecária da Universidade Federal do Paraná, Curitiba, Paraná, Brasil.

** Professora doutora da Universidade Federal do Paraná, Curitiba, Paraná, Brasil.

\section{Correspondência}

Eliane Maria Stroparo - Universidade Federal do Paraná, Reitoria, Biblioteca Central. Centro Politécnico

Jardim das Américas, CEP: 81531-970 - Curitiba, Paraná - Brasil.

E-mail: eliane@ufpr.br - laulaurac.moreira@gmail.com

Recebido em 26 de março de 2015

Aprovado em 13 de outubro de 2015 